\title{
COVID-19 induced mental suffering is more painful than physical suffering: an experience-based perspective
}

\author{
Habib Md Reazaul Karim \\ Affiliation: Department of Anesthesiology and Critical Care. All India Institute of Medical Sciences, Raipur. India. PIN- 492099 \\ Correspondence: Dr. Habib Md Reazaul Karim, Faculty Room A001, Block A. All India Institute of Medical Sciences, Raipur. India. \\ PIN-492099; E-mail: drhabibkarim@aiimsraipur.edu.in; Phone: +91961237258
}

\section{Abstract}

COVID-19 pandemic has affected the lives of billions of human beings, either directly or indirectly. The physical presentation of the disease and its course to cure, permanent residual structural damage or death has been well documented. Few aspects that have recently been emphasized are the COVID fatigue and the mental suffering, not only by the general population, the COVID patients but also the healthcare professionals who are deputed to look after these patients. This manuscript throws some light on this very important aspect with long lasting impact.

Keywords: COVID-19; Healthcare worker; Mental health; Stress

Citation: Karim HMR.COVID-19 induced mental suffering is more painful than physical suffering: an experiencebased perspective (Perspective). Anaesth. pain intensive care 2020;24(6):694-695

\section{Perspective}

It was apparently a bright sunny morning when my journey to the hospital, more precisely to my duty station in COVID ICU, started. On my way to ICU in the long hospital corridor, I spotted one of our nursing officers who was also going for duty in the same ICU. After exchanging morning greetings, she told me about a patient and her sad experience during her duty on the previous day. There was a patient in his early sixties and he tried to jump off from the window of the washroom situated on the 3rd floor of the hospital building. Somehow, he came into the notice of both the security staff on surveillance cameras and on-duty staff and subsequently was rescued. He neither looked very violent nor depressed. However, he appeared to be anxious and expressed his worries about his health and his family. Psychological counseling and management had already been started.

This news made my mind gloomy. The impact of the COVID-19 pandemic on personal and family life is a great concern, and has been largely overlooked. The story reminded me of our difficult time only a month ago when my wife, who also happens to be a doctor, was in her term pregnancy and tested positive for COVID-19. She was hospitalized where she delivered our second baby via emergency cesarean section and had to deal with the initial post-partum all alone. It was really a painful period for our family members. The physical suffering was evident; what was not evident but was more disturbing to all of us was the period of mental disharmony that we had to pass through. Filled in with all these not-so-good memories, I reached the designated duty area and took over the charge from the out-going team. There, I heard that extremely sorrowful news that the gentleman had jumped off from the window late in the night and despite all efforts could not be saved. During my COVID duty, I also came across a few patients who were violent and moody, who required antipsychotic and antidepressant drugs. Most of them had developed these symptoms and psychotic behavior only for the first time after contracting the disease.

The impact of the COVID-19 pandemic has been multi-dimensional on every stratum of the society. Literature indicates the presence of anxiety and 
depression in 16 to $28 \%$ population, and self-reported stress in up to $8 \%$ as common psychological reactions to the COVID-19 pandemic. $^{1}$ The healthcare delivery system has reached its maximal stretchable limit where it is facing an acute shortage of manpower and resources. Yet the mental health issue has emerged as another pandemic within the pandemic. This has been recognized the world over and even the World Health Organization (WHO), and the Centre for Disease Control and Prevention (CDC) have taken cognizance of it. ${ }^{2,3}$ The CDC indicates various factors including fear and worries about own health and the health of loved ones, about financial issues, job and the absence of any support services on which we could rely, as the cause of the same. ${ }^{2}$ The associated uncertainty and relatively low predictable course of COVID-19, coupled with a looming shortage of resources also contribute to emotional distress. ${ }^{4}$ The lack of definitive or effective pharmacotherapy has also crept into the mind of everyone leaving an impact on mental health. Forced social isolation has shown to lead to psychological illness. ${ }^{5}$ This is compounded by the economic uncertainty, unemployment, and lack of social security, ${ }^{1,3}$ especially for the poor families where the sole earning member is the sufferer. Although many families may not rely on a single bread winner, still all these concerns come to mind. The same psychological stress was experienced by me when I tested positive for corona following COVID ICU duty and got hospitalized with symptoms. Lack of family contact even on the death-bed, and not getting a proper funeral on the eternal journey is also a bitter and horrifying thought that comes into the mind. The future of dependents (children, elderly parents and/or other family members), and the stress and burden that the spouse would bear, in case something unexpected happen, results in sleepless nights.

While we need to mind our minds, it has become increasingly difficult for healthcare workers to cope up with the continued onslaught by the disease. They not only suffer from mental stress due to long duty hours in COVID-19 wards and over-work, but also pass through continual experience of misery and pain on witnessing the suffering of the patients and the scenes of death. While the stress on early identification of the symptoms and responding to it empathically through different ways and means, ${ }^{3}$ and the need for prevention and early intervention is stressed for all, ${ }^{6}$ it appears that healthcare providers, especially those who are away from their families, need special attention.

\section{Acknowledgment}

I acknowledge the help of my beloved wife Dr. Ghazal Ahmed for her pre-submission review and editing of the manuscript.

\section{Conflict of interest}

None declared by the author.

\section{References}

1. Rajkumar RP. COVID-19 and mental health: A review of the existing literature. Asian $J$ Psychiatr. 2020;52:102066. DOI:10.1016/j.ajp.2020.102066. PMID: 32302935.

2. Centre for Disease Control and prevention. Mental health and Coping with COVID-19. Atlanta: CDC; July 1, 2020. [cited Sept 25, 2020]. Available from: https://www.cdc.gov/coronavirus/2019-ncov/daily-lifecoping/managing-stress-anxiety.html

3. Inter-Agency Standing Committee. Basic Psychosocial Skills: A guide for COVID-19 responders. Geneva: World Health Organization; June 1, 2020.pp6-23. [cited Sept 25, 2020] Available from https://interagencystandingcommittee.org/iascreference-group-mental-health-and-psychosocialsupport-emergency-settings/iasc-guidance-basic

4. Pfefferbaum B, North CS. Mental Health and the Covid19 Pandemic. N Engl J Med. 2020 Aug 6;383(6):510512. DOI: $10.1056 / N E J M p 2008017$

5. Kato TA, Sartorius N, Shinfuku N. Forced social isolation due to COVID-19 and consequent mental health problems: Lessons from hikikomori. Psychiatry Clin Neurosci. 2020 Sep;74(9):506-507. [PubMed] DOI: 10.1111/pcn.13112

6. Vinkers $\mathrm{CH}$, van Amelsvoort $\mathrm{T}$, Bisson JI, Branchi I, Cryan JF, Domschke K, et al. Stress resilience during the coronavirus pandemic. Eur Neuropsychopharmacol. 2020 Jun;35:12-16. [PubMed] DOI: 10.1016/j.euroneuro.2020.05.003

7. Galea S, Merchant RM, Lurie N. The Mental Health Consequences of COVID-19 and Physical Distancing: The Need for Prevention and Early Intervention. JAMA Intern Med. 2020 Jun 1;180(6):817-818. [PubMed] DOI: 10.1001/jamainternmed.2020.1562 